\title{
Is $\mathrm{R}_{2}{ }^{*}$ a New MRI Biomarker for the Progression of Parkinson's Disease? A Longitudinal Follow-Up
}

\author{
Miguel Ulla ${ }^{1,2 *}$, Jean Marie Bonny ${ }^{3}$, Lemlih Ouchchane ${ }^{4,5}$, Isabelle Rieu ${ }^{1,2}$, Beatrice Claise ${ }^{2,6}$, \\ Franck Durif ${ }^{1,2}$
}

1 CHU Clermont-Ferrand, Service de Neurologie A, Clermont-Ferrand, France, 2 University Clermont 1, EA3845, Clermont-Ferrand, France, 3 INRA, UR370 Qualité des Produits Animaux, Saint Genès Champanelle, France, $4 \mathrm{CHU}$ Clermont-Ferrand, Pôle Santé Publique Médecine Légale Qualité Vigilances, Unité de Biostatistique Informatique Médicale et Technologies de Communication, Clermont-Ferrand, France, $\mathbf{5}$ University Clermont1, Laboratoire de Biostatistique Informatique Médicale et Technologies de Communication, Clermont-Ferrand, France, 6 CHU Clermont-Ferrand, Service de Radiologie B, Clermont-Ferrand, France

\begin{abstract}
Purpose: To study changes of iron content in basal ganglia in Parkinson's disease (PD) through a three-year longitudinal follow-up of the effective transverse relaxation rate $\mathrm{R}_{2}{ }^{*}$, a validated MRI marker of brain iron content which can be rapidly measured under clinical conditions.

Methods: Twenty-seven PD patients and 26 controls were investigated by a first MRI $\left(\mathrm{t}_{0}\right)$. Longitudinal analysis was conducted among the 18 controls and 14 PD patients who underwent a second MRI $\left(t_{1}\right) 3$ years after. The imaging protocol consisted in 6 gradient echo images obtained at different echo-times for mapping $\mathrm{R}_{2}{ }^{*}$. Quantitative exploration of basal ganglia was performed by measuring the variation of $R_{2}{ }^{*}\left[R_{2}{ }^{*}\left(t_{1}\right)-R_{2}{ }^{*}\left(t_{0}\right)\right]$ in several regions of interest.

Results: During the three-year evolution of $\mathrm{PD}, \mathrm{R}_{2}{ }^{*}$ increased in Substantia nigra (SN) (by $10.2 \%$ in pars compacta, $\mathrm{p}=0.001$, and $8.1 \%$ in pars reticulata, $p=0.013)$ and in the caudal putamen $(11.4 \%, p=0.011)$, without significant change in controls. Furthermore, we showed a positive correlation between the variation of $\mathrm{R}_{2}{ }^{*}$ and the worsening of motor symptoms of PD $(p=0.028)$.

Conclusion: Significant variation of $\mathrm{R}_{2}{ }^{*}$ was longitudinally observed in the $\mathrm{SN}$ and caudal putamen of patients with PD evolving over a three-year period, emphasizing its interest as a biomarker of disease progression. Our results suggest that $\mathrm{R}_{2}{ }^{*} \mathrm{MRI}$ follow-up could be an interesting tool for individual assessment of neurodegeneration due to PD, and also be useful for testing the efficiency of disease-modifying treatments.
\end{abstract}

Citation: Ulla M, Bonny JM, Ouchchane L, Rieu I, Claise B, et al. (2013) Is $\mathrm{R}_{2}{ }^{*}$ a New MRI Biomarker for the Progression of Parkinson's Disease? A Longitudinal Follow-Up. PLoS ONE 8(3): e57904. doi:10.1371/journal.pone.0057904

Editor: John Duda, Philadelphia VA Medical Center, United States of America

Received August 7, 2012; Accepted January 29, 2013; Published March 1, 2013

Copyright: ( 2013 Ulla et al. This is an open-access article distributed under the terms of the Creative Commons Attribution License, which permits unrestricted use, distribution, and reproduction in any medium, provided the original author and source are credited.

Funding: The authors have no funding or support to report.

Competing Interests: The authors have declared that no competing interests exist.

* E-mail: mulla@chu-clermontferrand.fr

\section{Introduction}

Increased iron concentration was found in specific brain structures of patients suffering from Parkinson's disease (PD). Indeed, post mortem histological analysis [1], in vivo magnetic resonance imaging (MRI) [2-7] and transcranial sonography [8] studies are in agreement, highlighting iron deposition in the substantia nigra (SN) of PD patients, although results are controversial for other basal ganglia (BG) structures such as the putamen [9-11]. Whereas no association was shown between iron deposition and disease duration, clinical scores correlated with SN iron load in PD patients $[4,5,12]$, suggesting that the amount of $\mathrm{SN}$ iron could be a biomarker of disease severity.

It is noteworthy that since there is no longitudinal data available in PD, all these results come from cross-sectional studies that do not directly assess changes in the amounts of iron in the brains of subjects over time. Thus, to further investigate the link between brain iron changes and PD progression, a longitudinal approach involving both PD patients and normal subjects appears to be the most appropriate study design for distinguishing between the concomitant effects of normal aging and disease evolution over time. Indeed, the amount of iron increases particularly in the caudate nucleus, putamen [13-16] and cerebral cortex [17] during normal aging.

Magnetic resonance imaging (MRI) is a non invasive imaging modality which makes it interesting for conducting longitudinal follow-ups. Moreover, it is a powerful tool for detecting iron deposits in the brain. Iron deposition induces local, fluctuating and non-fluctuating, magnetic field inhomogeneities which lead to faster signal decay and thus to an increase of the relating relaxation rates [18]. First, the relaxation rate $R_{2}\left(R_{2}=1 / T_{2}\right)$ is influenced by the effects of fluctuating microscopic magnetic field due to iron. The measurement of $R_{2}$ is based on spin-echoes which discard the non-fluctuating magnetic field inhomogeneities whereas the fluctuating ones are preserved. It explains why iron effects are detectable through $\mathrm{R}_{2}$ variations. Secondly, the relaxation rate $R_{2}$ ' conveys the other non-fluctuating magnetic field effects due to iron. The latter are also measurable through $\mathrm{R}_{2}$, 
variations using gradient-echoes [19]. It has been shown that $\mathbf{R}_{2}$ and $\mathrm{R}_{2}$ ' exhibit a strong correlation with iron concentration, with similar sensitivities [20]. Since reversible and irreversible iron effects cumulate through $\mathrm{R}_{2}$, which sums these two relaxation rates, this parameter is characterized by a higher sensitivity to iron content. This is why we propose to assess $R_{2}{ }^{*}$ as an imaging biomarker of PD evolution.

To achieve this, a 3-year follow-up longitudinal study was conducted on cohorts of PD patients and controls for dissociating the effects of disease progression and normal aging in regional variations of $R_{2} *$ in basal ganglia (BG).

\section{Methods}

\section{Subjects}

Twenty-seven PD patients were included in the study. They were recruited consecutively, among patients who presented themselves for consultation in the Movement Disorder unit of Clermont-Ferrand, France. All the patients were suffering from idiopathic Parkinson's disease according to the criteria of the "Parkinson's Disease Society Brain Bank" [21]. In addition, twenty-six control subjects were included, recruited among relatives of patients, who were all free of any history of neurological or psychiatric diseases.

All the subjects were interviewed regarding their previous medical history and a Mini Mental Status examination was performed to exclude demented subjects $(\mathrm{MMS}<26 / 30)$. In the PD group, disease duration, levodopa equivalent dose (LED) [22], Hoehn and Yahr (HY) stages and the motor part of Unified Parkinson's Disease Rating Scale (UPDRS III) [23], were noted, the latter two being assessed in the "on" state. The lateralized UPDRS motor score on each side was also calculated (sum of items 20 to 26).

All the subjects were investigated by an initial MRI session (called t0). Three years later the subjects were contacted by mail or phone to participate in a second MRI session, to enable us to conduct a longitudinal analysis. After acceptance, 18 controls and 14 PD patients underwent this second MRI session (called tl). Thus 13 PD patients (1 death due to heart attack, 3 benefiting from deep-brain stimulation, 1 refusal and 8 moves) and 8 controls (unavailability) did not have the second MRI.

All subjects gave written consent and the study was approved by the local research ethics committee (Comite de Protection des Personnes Sud-Est, file AU 867).

\section{MRI Investigations}

Images were obtained using a $1.5 \mathrm{~T}$ MRI system (Sonata, Siemens, Germany). The subjects were immobilized in the head coil for both emission and reception, by foam pads to reduce involuntary head movements. Disposable ear protectors were also used to reduce acoustic noise.

A $\mathrm{T}_{1}$-weighted sagittal scout image was first acquired to locate the anterior and posterior commissure (AC and PC). Then, an anatomical protocol was used to highlight BG structures in 14 slices acquired parallel to the AC-PC line.

Finally, we used a 2D steady-state free precession gradient echo sequence for mapping the apparent proton transverse relaxation rate $\left(\mathrm{R}_{2} *=1 / \mathrm{T}_{2} *\right)$. For each of the 14 slices of the anatomical dataset, images were obtained at 6 different echo times (TE) ranging from $7.61 \mathrm{~ms}$ to $50 \mathrm{~ms}(7.61,10,20,30,40,50 \mathrm{~ms})$. The other image parameters were: $\mathrm{TR}=1050 \mathrm{~ms}, \mathrm{FOV}=280 \times 280$ $\mathrm{mm}^{2}$, matrix $=128 \times 128$, slice thickness $=2.5 \mathrm{~mm}($ volume of the resulting voxel $2.2 \times 2.2 \times 2.5 \mathrm{~mm}^{3}$ ). The duration of the whole MRI session was 40 minutes.

\section{Image Analysis}

Regions of interest (ROI) in which $\mathrm{R}_{2}{ }^{*}$ was measured were defined manually on the anatomical images using Image J, a public domain software application (http://rsb.info.nih.gov/ij/). This approach was preferred to automatic segmentation because it is the only method able to subdivide SN into two parts (pars reticulata and pars compacta) [24]. The investigator responsible for ROI definition (M.U.) was unaware of subject group identification. The accurate position of each ROI was systematically controlled in the images obtained at the different TE and for the two MRI of the same subject based on relative distance of the ROI to the boundaries of the anatomical structure. The shape and size of the ROI were identical for a given structure in all subjects. Three BG structures were selected (Figure 1): the SN divided into two parts: pars reticulata and pars compacta $(\mathrm{SNr}$ and $\mathrm{SNc}$ respectively); according to recent data [5]; the putamen, also divided into two parts: rostral and caudal (rPut and cPut respectively); and the globus pallidus (GP). Grey matter (GM) and white matter $(\mathrm{WM})$, both in the frontal lobe, were also studied. All ROI were placed bilaterally.

$\mathrm{R}_{2}$ * values from the different brain structures were obtained by fitting the ROI-averaged magnitude of the six echoes with a single exponential decay using a nonlinear least-squares numerical procedure.

\section{Statistical Analysis}

PD patients were compared to controls regarding gender (using Fisher's exact test) and continuous characteristics such as age and period between $t_{0}$ and $t_{1}$ examinations (using the Wilcoxon test).

$\mathrm{R}_{2}$ * values measured in the left and right hemispheres (in controls) as well as in the more and less affected side (in PD patients) in each brain structure were not significantly different (paired signed rank tests). Therefore these two measurements were averaged to obtain a single representative value in each structure. Quantitative variables were transformed into ordinal classes (age in quartiles, disease duration, HY stage and UPDRS in terciles) for inclusion as factors in ANOVAs. The effect of different variables on $\mathrm{R}_{2}{ }^{*}$ at $\mathrm{t}_{0}$ was tested separately for each ROI and each group by analysis of variance (ANOVA); i.e. gender and age for all groups of subjects, and disease duration, HY stage and UPDRS for the PD group only. In the case of significant effect, a post-hoc multiple comparisons procedure was performed (Tukey test).

Subjects who benefited from two MRI sessions $(\mathrm{n}=32)$ were used to assess the possible difference between $R_{2}{ }^{*}$ values by performing a signed rank test after computation of $\Delta R_{2} *$ defined as the difference $\mathrm{R}_{2} *\left(\mathrm{t}_{1}\right)-\mathrm{R}_{2} *\left(\mathrm{t}_{0}\right)$.

Furthermore, disease effect was tested for both $\mathrm{R}_{2} *$ at $\mathrm{t}_{0}$ and $\Delta \mathrm{R}_{2}$ * through ANOVA involving PD patients (PD) and controls.

Finally, correlations between $\Delta \mathrm{R}_{2} *$ and variations of $\mathrm{HY}$ stages, $\Delta \mathrm{HY}\left(\mathrm{HY}^{*}\left(\mathrm{t}_{1}\right)-\mathrm{HY}^{*}\left(\mathrm{t}_{0}\right)\right)$, variations of LED, $\Delta \mathrm{LED}\left(\mathrm{LED}\left(\mathrm{t}_{1}\right)-\right.$ LED $\left.\left(\mathrm{t}_{0}\right)\right)$ and percentage changes of UPDRS III worsening ( $\triangle$ UPDRS, \%) were tested using a Spearman correlation.

All these statistical tests were performed on SAS (SAS v9.1, SAS institute inc., Cary, NC, USA) with a 0.05 type I error.

\section{Results}

\section{Subjects}

Table 1 summarizes the demographic and clinical characteristics of subjects.

When comparing the characteristics of control and PD groups, no significant difference was found in age $(p=0.314)$, gender $(p=0.264)$ and in the period between the two MRI sessions $(\mathrm{p}=0.819)$. 


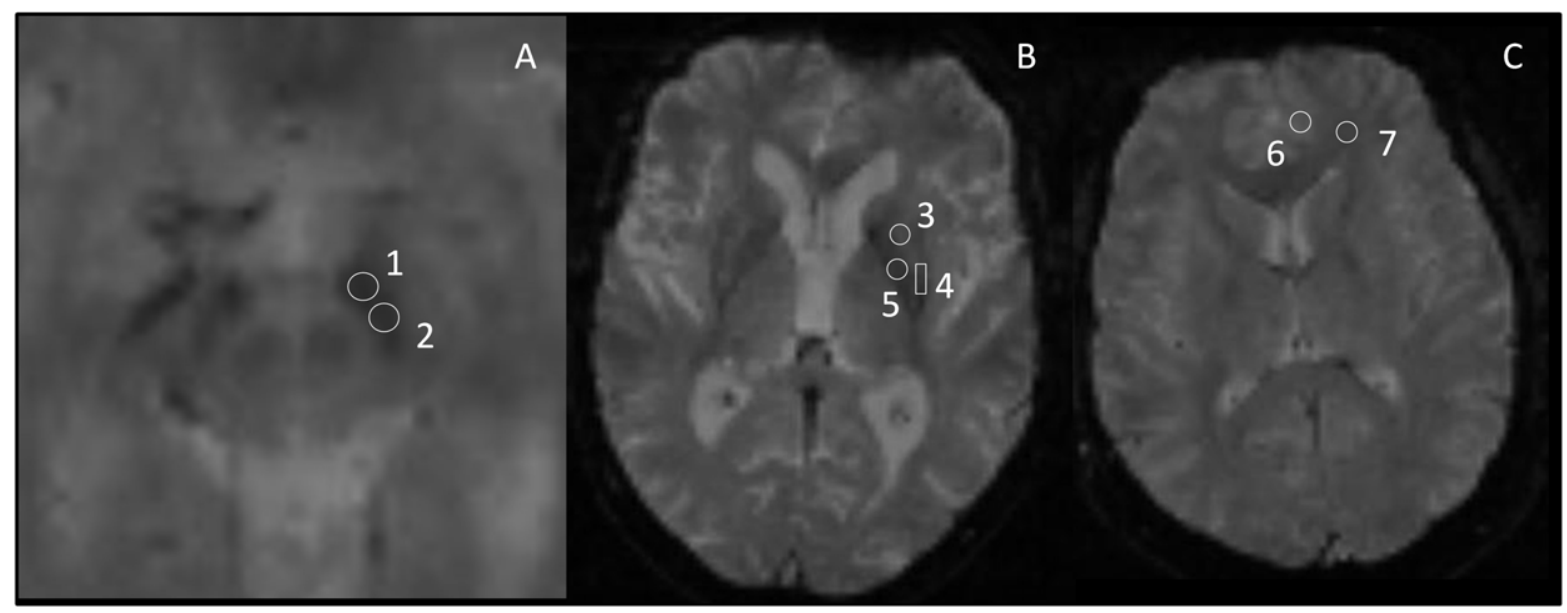

Figure 1. ROI location in three different slices (A, B and C) in anatomic images. $T R=1100 \mathrm{~ms}, \mathrm{TE}=50 \mathrm{~ms}$, field-of-view $(F O V)=280 \times 280$ $\mathrm{mm}$, acquisition matrix $=256 \times 256$ 1: Substantia nigra pars reticulata (SNr). 2: Substantia nigra pars compacta (SNc). 3: rostral putamen (rPut). 4: caudal putamen (cPut). 5: Globus Pallidus (GP). 6: gray matter (GM). 7: white matter (WM).

doi:10.1371/journal.pone.0057904.g001

The LED was $614 \pm 317 \mathrm{mg}$ at $\mathrm{t}_{0}$ and $907 \pm 443 \mathrm{mg}$ at $\mathrm{t}_{1}$, with a significant increase between $t_{0}$ and $t_{1}(p=0.019)$. The HY scale and the UPDRS III in PD patients followed-up longitudinally were significantly higher at $t_{1}$ compared to $t_{0}$, reflecting disease evolution (HY, $\mathrm{p}=0.007$; UPDRS, $\mathrm{p}<0.0001$ ).

The comparisons between subjects investigated only at $\mathrm{t}_{0}$ and subjects investigated twice did not reveal any significant difference regarding age $(p=0.667$ for controls and $p=1$ for PD patients) and gender ( $p=0.118$ for controls and $p=1$ for PD patients) in all subjects, either regarding disease duration $(p=0.099)$, HY stage $(p=0.506)$ and UPDRS III $(p=0.101)$ in PD patients.

It should be noted that anatomical MRI sequences in all our subjects did not display any anomalies, in particular vascular lesions.

\section{Cross-sectional Analysis of $\mathrm{R}_{2}{ }^{*}$}

Measurements performed at $t_{0}$ on controls showed that $\mathrm{R}_{2}{ }^{*}$ was higher in older subjects (Table 2). The effect of age turned out to be significant in the cPut $(\mathrm{f}=5.39, \mathrm{p}=0.007)$ and the GM $(\mathrm{f}=4.39, \mathrm{p}=0.016)$. Post-hoc analysis showed that the difference was significant between first three quartiles and last quartile, in both cPut and GM. Moreover, no effect of gender on $\mathrm{R}_{2}{ }^{*}$ was found.

In PD patients, a significant effect of age in the $\mathrm{rPut}(\mathrm{f}=4.4$, $p=0.019)$ was observed. Post-hoc comparisons revealed higher $\mathrm{R}_{2} *$ values in the fourth quartile of age compared to the others. We also showed a trend of lower $\mathrm{R}_{2} *$ in $\mathrm{WM}(\mathrm{f}=3.08, \mathrm{p}=0.057)$.
Gender, disease duration, HY stage and UPDRS III did not have significant effects on $\mathrm{R}_{2} *$ at $\mathrm{t}_{0}$ (Table 2).

Finally, the intergroup comparison at $\mathrm{t}_{0}$ with ANOVA showed a significant effect of $\mathrm{PD}$ on $\mathrm{R}_{2} *$ in $\mathrm{SNr}(\mathrm{f}=6.55, \mathrm{p}=0.013)$ and $\mathrm{SNc}$ ( $\mathrm{f}=15.49, \mathrm{p}<0.001$ ), $\mathrm{R}_{2}$ * being higher in the $\mathrm{PD}$ group. Also, $\mathrm{R}_{2}{ }^{*}$ tended to be lower in the WM of PD patients $(\mathrm{f}=3.08, \mathrm{p}=0.085)$ (Figure 2).

\section{Longitudinal Analysis of $\mathrm{R}_{2}{ }^{*}$}

For controls, no significant evolution over 3 years was found. $\Delta \mathrm{R}_{2} *$ tended to be significant in WM with $\mathrm{R}_{2}{ }^{*}$ decreasing by $0.82 \pm 0.44 \mathrm{~s}^{-1}(\mathrm{p}=0.099)$.

For PD patients, $\mathrm{R}_{2} *$ increased by $2.32 \pm 0.63 \mathrm{~s}^{-1}(10.2 \%)$ in $\mathrm{SNc}(\mathrm{p}=0.001), 2.19 \pm 0.95 \mathrm{~s}^{-1}(8.1 \%)$ in $\mathrm{SNr}(\mathrm{p}=0.042)$ and $2.56 \pm 0.8 \mathrm{~s}^{-1}(11.4 \%)$ in the cPut $(\mathrm{p}=0.011)$, while it decreased by $1.21 \pm 0.44 \mathrm{~s}^{-1}(7.5 \%)$ in WM $(\mathrm{p}=0.042)$.

Concerning the comparison between controls and PD patients, $\Delta \mathrm{R}_{2} *$ in $\mathrm{PD}$ changed significantly from that of controls in $\mathrm{SNc}$ $(\mathrm{f}=12.1, \mathrm{p}=0.002), \mathrm{SNr}(\mathrm{f}=5.05, \mathrm{p}=0.033)$ and in the $\mathrm{cPut}$ $(\mathrm{f}=5.91, \mathrm{p}=0.022)$. It should be noted that there was no difference of $\Delta \mathrm{R}_{2} *$ between $\mathrm{PD}$ and controls in WM. The results of the longitudinal studies are grouped in Figure 3.

Finally, we found a positive correlation between $\Delta \mathrm{R}_{2} *$ and $\triangle \mathrm{UPDRS}$ in $\mathrm{SNc}(\mathrm{R}=0.586, \mathrm{p}=0.028)$ and $\mathrm{SNr}(\mathrm{R}=0.608$, $\mathrm{p}=0.021)($ Figure 4$)$, but no correlation between $\Delta \mathrm{R}_{2} *$ and $\Delta \mathrm{HY}$ nor between $\Delta \mathrm{R}_{2}{ }^{*}$ and $\triangle \mathrm{LED}$.

Table 1. Demographic and clinical characteristics of subjects.

\begin{tabular}{|c|c|c|c|c|c|c|c|c|c|c|}
\hline group & $n\left(t_{0}\right)$ & $\begin{array}{l}\text { age } \\
\text { (years) }\end{array}$ & $\begin{array}{l}\text { gender } \\
\text { (M/F) }\end{array}$ & $\begin{array}{l}\text { disease duration } \\
\text { (years) }\end{array}$ & $\begin{array}{l}\text { HY stage } \\
\left(t_{0}\right)\end{array}$ & $\begin{array}{l}\text { UPDRS III } \\
\left(t_{0}\right)\end{array}$ & $n\left(t_{1}\right)$ & $\begin{array}{l}\text { delay between } \\
2 \text { MRI (months) }\end{array}$ & $\begin{array}{l}\text { HY } \\
\text { stage }\left(t_{1}\right)\end{array}$ & $\begin{array}{l}\text { UPDRS III } \\
\left(t_{1}\right)\end{array}$ \\
\hline $\begin{array}{l}\text { PD } \\
\text { patients }\end{array}$ & 27 & $60.2 \pm 10.7$ & $13 / 14$ & $5.7 \pm 4.4$ & $1.9 \pm 0.7$ & $12.1 \pm 8.5$ & 14 & $36.9 \pm 4.7$ & $2.5 \pm 0.5^{*}$ & $19.8 \pm 14.7^{* *}$ \\
\hline controls & 26 & $57.0 \pm 8.5$ & 9/17 & NA & NA & NA & 18 & $37.2 \pm 3.7$ & NA & NA \\
\hline
\end{tabular}

Mean \pm standard error. $\mathrm{M}=$ male; $\mathrm{F}=$ female; $\mathrm{NA}=$ not applicable; $\mathrm{HY}=$ Hoehn and Yahr; UPDRS III= motor part of UPDRS (Unified Parkinson's Disease Rating Scale). ${ }^{*} p<0.01$ and ${ }^{* *} p<0.0001$, vs. $t_{0}$ (signed rank test).

doi:10.1371/journal.pone.0057904.t001 
Table 2. $R_{2}^{*}\left(s^{-1}\right)$ at $t_{0}$ in each $\mathrm{ROI}$ (mean \pm standard error).

\begin{tabular}{|c|c|c|c|c|c|c|c|c|c|c|}
\hline & & $t / q$ & $\mathbf{n}$ & GM & GP & SNc & $\mathrm{SNr}$ & WM & rPut & cPut \\
\hline controls & age & 1 & 8 & $12.46 \pm 0.34$ & $25.81 \pm 0.59$ & $21.47 \pm 0.53$ & $25.79 \pm 0.62$ & $17.13 \pm 0.32$ & $18.98 \pm 0.57$ & $21.67 \pm 0.35$ \\
\hline \multirow[t]{9}{*}{$(n=26)$} & & 2 & 7 & $11.61 \pm 0.53$ & $23.73 \pm 0.67$ & $20.56 \pm 0.52$ & $25.23 \pm 0.91$ & $16.25 \pm 0.32$ & $18.74 \pm 0.70$ & $20.96 \pm 0.66$ \\
\hline & & 3 & 6 & $12.10 \pm 0.28$ & $24.45 \pm 1.15$ & $19.66 \pm 0.48$ & $23.87 \pm 0.81$ & $16.38 \pm 0.76$ & $19.41 \pm 1.13$ & $21.22 \pm 0.80$ \\
\hline & & 4 & 5 & $14.03 \pm 0.68$ & $24.97 \pm 1.32$ & $20.89 \pm 0.86$ & $25.45 \pm 1.35$ & $17.18 \pm 0.52$ & $20.33 \pm 0.86$ & $26.17 \pm 1.55$ \\
\hline & $F$ & & & 4.39 & 0.6 & 1.29 & 1.02 & 1.25 & 0.69 & 5.39 \\
\hline & $p$ & & & $0.0165^{*}$ & 0.6237 & 0.3072 & 0.4063 & 0.3208 & 0.5708 & $0.0074^{*}$ \\
\hline & gender & $\mathrm{F}$ & 18 & $12.56 \pm 0.36$ & $25.03 \pm 0.54$ & $20.91 \pm 0.39$ & $25.07 \pm 0.43$ & $16.60 \pm 0.27$ & $19.67 \pm 0.42$ & $22.82 \pm 0.71$ \\
\hline & & M & 8 & $12.19 \pm 0.35$ & $24.21 \pm 0.82$ & $20.20 \pm 0.41$ & $25.28 \pm 1.10$ & $17.01 \pm 0.49$ & $18.38 \pm 0.80$ & $20.92 \pm 0.49$ \\
\hline & $F$ & & & 0.15 & 0.51 & 0.12 & 0.88 & 2.46 & 2.48 & 0.51 \\
\hline & $p$ & & & 0.702 & 0.4858 & 0.7286 & 0.3612 & 0.1331 & 0.1316 & 0.4827 \\
\hline $\begin{array}{l}\text { PD } \\
\text { patients }\end{array}$ & age & 1 & 8 & $11.65 \pm 0.54$ & $25.93 \pm 0.72$ & $23.60 \pm 0.69$ & $27.14 \pm 0.82$ & $15.81 \pm 0.49$ & $18.44 \pm 0.46$ & $20.34 \pm 0.90$ \\
\hline \multirow[t]{24}{*}{$(n=27)$} & & 2 & 5 & $12.12 \pm 0.70$ & $25.87 \pm 1.61$ & $22.27 \pm 0.61$ & $27.43 \pm 2.24$ & $17.25 \pm 0.61$ & $18.20 \pm 0.51$ & $22.63 \pm 1.50$ \\
\hline & & 3 & 7 & $12.34 \pm 0.62$ & $24.07 \pm 0.53$ & $21.11 \pm 0.64$ & $25.44 \pm 0.89$ & $16.34 \pm 0.46$ & $18.40 \pm 0.70$ & $22.09 \pm 1.07$ \\
\hline & & 4 & 7 & $11.54 \pm 0.87$ & $25.07 \pm 1.19$ & $23.32 \pm 0.76$ & $28.26 \pm 1.08$ & $15.29 \pm 0.55$ & $22.33 \pm 1.17$ & $24.91 \pm 1.46$ \\
\hline & $F$ & & & 0.22 & 0.07 & 1.26 & 1.32 & 3.08 & 4.4 & 1.76 \\
\hline & $p$ & & & 0.8787 & 0.9753 & 0.3225 & 0.3028 & 0.0575 & $0.0194^{*}$ & 0.1944 \\
\hline & gender & $\mathrm{F}$ & 14 & $12.15 \pm 0.48$ & $24.18 \pm 0.44$ & $22.54 \pm 0.61$ & $25.54 \pm 0.50$ & $16.00 \pm 0.36$ & $19.37 \pm 0.74$ & $22.23 \pm 0.97$ \\
\hline & & M & 13 & $11.61 \pm 0.47$ & $26.33 \pm 0.81$ & $22.74 \pm 0.48$ & $28.66 \pm 0.94$ & $16.17 \pm 0.44$ & $19.42 \pm 0.71$ & $22.59 \pm 0.93$ \\
\hline & $F$ & & & 0,01 & 1,52 & 0,1 & 2,12 & 0,6 & 0,57 & 1,54 \\
\hline & $p$ & & & 0,9081 & 0,2361 & 0,7576 & 0,1649 & 0,4506 & 0,4625 & 0,2327 \\
\hline & diseases duration & 1 & 10 & $11.83 \pm 0.53$ & $25.54 \pm 0.74$ & $22.64 \pm 0.71$ & $26.71 \pm 0.51$ & $15.36 \pm 0.38$ & $18.65 \pm 0.80$ & $22.09 \pm 1.32$ \\
\hline & & 2 & 9 & $11.40 \pm 0.46$ & $25.55 \pm 1.02$ & $23.12 \pm 0.54$ & $26.48 \pm 0.79$ & $16.61 \pm 0.37$ & $20.57 \pm 0.92$ & $22.86 \pm 1.13$ \\
\hline & & 3 & 8 & $12.51 \pm 0.74$ & $24.44 \pm 0.80$ & $22.07 \pm 0.77$ & $28.09 \pm 1.74$ & $16.39 \pm 0.65$ & $18.99 \pm 0.82$ & $22.29 \pm 0.99$ \\
\hline & $F$ & & & 0.17 & 0.74 & 0.02 & 2.02 & 3.16 & 1.02 & 1.37 \\
\hline & $p$ & & & 0.8464 & 0.4936 & 0.983 & 0.1647 & 0.0696 & 0.3831 & 0.282 \\
\hline & Hoehn and Yahr & 1 & 9 & $11.81 \pm 0.58$ & $24.31 \pm 0.47$ & $22.23 \pm 0.79$ & $26.68 \pm 0.50$ & $15.83 \pm 0.43$ & $18.78 \pm 0.97$ & $21.85 \pm 1.39$ \\
\hline & & 2 & 9 & $11.54 \pm 0.43$ & $26.33 \pm 0.70$ & $23.12 \pm 0.48$ & $27.78 \pm 0.93$ & $16.06 \pm 0.41$ & $19.73 \pm 0.64$ & $22.32 \pm 0.85$ \\
\hline & & 3 & 9 & $13.34 \pm 0.89$ & $22.85 \pm 0.73$ & $21.62 \pm 0.98$ & $24.99 \pm 1.55$ & $16.66 \pm 0.76$ & $19.34 \pm 1.62$ & $23.83 \pm 1.71$ \\
\hline & $F$ & & & 1.98 & 2.37 & 0.15 & 0.43 & 1.09 & 0.07 & 1.01 \\
\hline & $p$ & & & 0.1708 & 0.1257 & 0.8614 & 0.6598 & 0.3594 & 0.9285 & 0.3875 \\
\hline & UPDRS III & 1 & 8 & $12.40 \pm 0.54$ & $25.65 \pm 0.88$ & $23.05 \pm 0.82$ & $27.07 \pm 1.51$ & $16.49 \pm 0.97$ & $19.96 \pm 0.87$ & $22.89 \pm 1.16$ \\
\hline & & 2 & 10 & $11.99 \pm 0.51$ & $25.63 \pm 0.74$ & $22.64 \pm 0.65$ & $27.05 \pm 0.57$ & $15.79 \pm 0.47$ & $18.04 \pm 0.29$ & $20.95 \pm 1.05$ \\
\hline & & 3 & 9 & $11.31 \pm 0.67$ & $24.37 \pm 0.95$ & $22.25 \pm 0.59$ & $27.00 \pm 1.13$ & $16.03 \pm 0.58$ & $20.39 \pm 1.15$ & $23.58 \pm 1.16$ \\
\hline & $F$ & & & 1.21 & 0.35 & 0.03 & 0.18 & 0.71 & 1 & 0.96 \\
\hline & $p$ & & & 0.3227 & 0.7077 & 0.9674 & 0.8399 & 0.5077 & 0.3883 & 0.4034 \\
\hline
\end{tabular}

$\mathrm{n}=$ number of subjects. Age was divided into quartiles (q) (the classes for controls being 42-49, 50-53, 54-67, 68-76; for PD patients 42-49, 50-59, 60-68, 69-78) and disease duration, Hoehn and Yahr stage and UPDRS III in terciles (t) (the classes for disease duration being 1-3, 4-6, 7-21; for HY 1-1.5, 2, 2.5-4; for UPDRS III 4-7.5, 8$12.5,13-40)$

$\mathrm{GM}=$ gray matter; $\mathrm{GP}=$ Globus Pallidus; $\mathrm{SNc}=$ Substantia nigra pars compacta; $\mathrm{SNr}=$ Substantia nigra pars reticulata; $\mathrm{WM}=$ white matter; $r$ Put $=$ rostral putamen; CPut $=$ caudal putamen.

${ }^{*} p<0.05$; analysis of variance (ANOVA). Post-hoc multiple comparisons (Tukey test) showed in the three cases that the difference was significant between the three first quartiles and the fourth.

doi:10.1371/journal.pone.0057904.t002

\section{Discussion}

Using an adapted longitudinal analysis, we show for the first time: $\mathrm{i}$ - how quickly $\mathrm{R}_{2}{ }^{*}$ increases due to the disease, since over 3 years it evolved by $10.2 \%$ in $\mathrm{SNc}, 8.1 \%$ in $\mathrm{SNr}$ and $11.2 \%$ in the cPut; ii- a positive correlation between $\Delta \mathrm{R}_{2} *$ and disease worsening assessed with motor part of UPDRS. We also confirm that $\mathrm{R}_{2}$ * increased in the $\mathrm{SN}$ of PD patients compared to controls.
Our results therefore suggest that $\mathrm{R}_{2}{ }^{*}$, previously considered as being a disease marker, is also sensitive to its evolution.

\section{Cross-sectional Analysis at $t_{0}$}

We confirm that $\mathrm{R}_{2} *$ is significantly higher in the $\mathrm{SN}$ of $\mathrm{PD}$ patients and that no changes had occurred in the others parts of $\mathrm{BG}$, in agreement with previous $\mathrm{R}_{2}{ }^{*}$-based cross-sectional studies $[3,7,9]$. Despite obvious anatomical differences between the two 


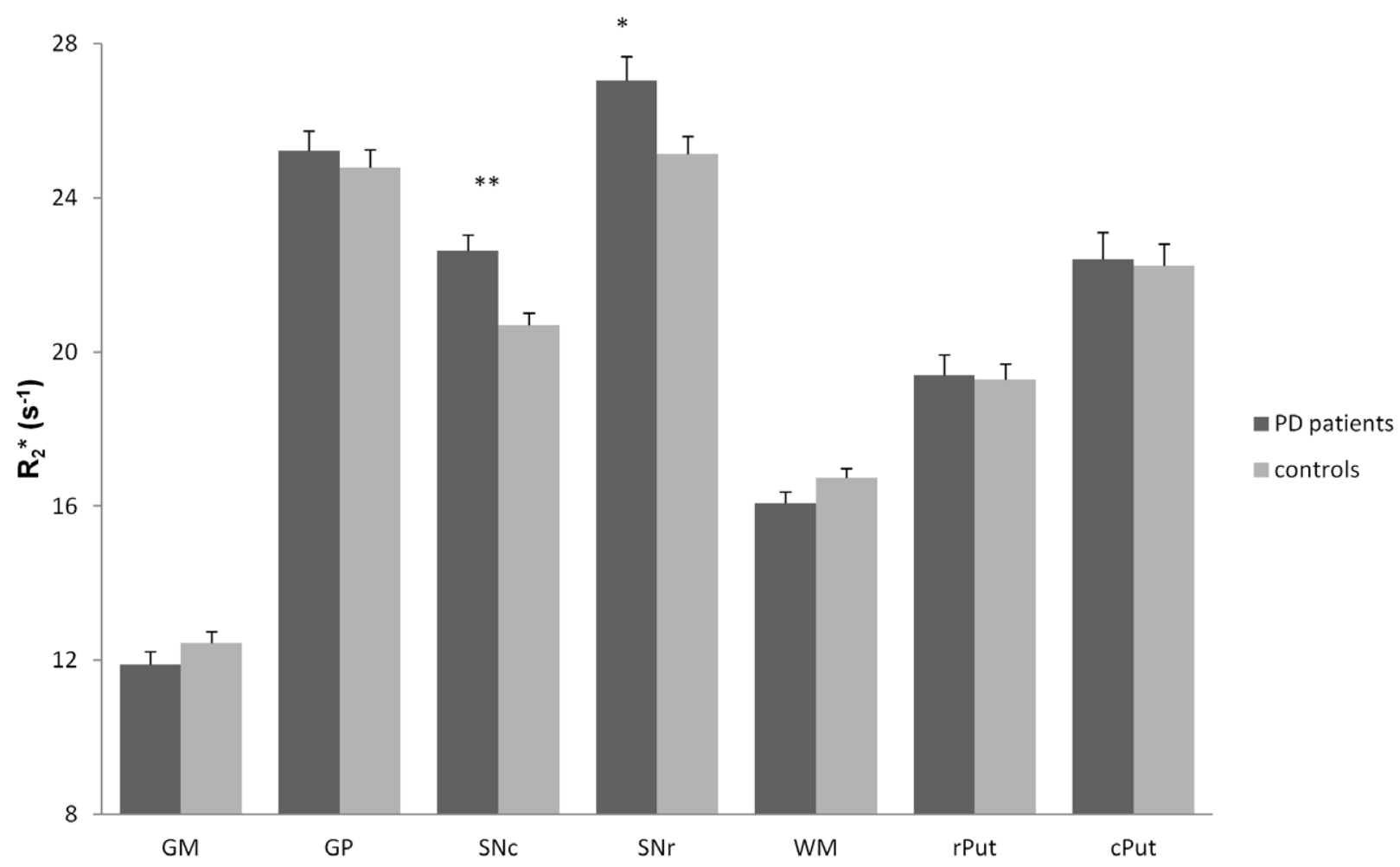

Figure 2. $\mathbf{R}_{\mathbf{2}}{ }^{*}\left(\mathbf{s}^{-1}\right)$ at $\mathbf{t}_{\mathbf{0}}$ in each $\mathbf{R O I}$ (mean \pm standard error) in PD patients and controls. GM=gray matter; GP=Globus Pallidus; $\mathrm{SNC}=$ Substantia nigra pars compacta; $\mathrm{SNr}=$ Substantia nigra pars reticulata; $\mathrm{WM}=$ white matter; $r$ Put $=$ rostral putamen; $c$ Put $=$ caudal putamen. ${ }^{* *}$ : $\mathrm{p}<0.001 ; * \mathrm{p}<0.05$; analysis of variance (ANOVA). doi:10.1371/journal.pone.0057904.g002

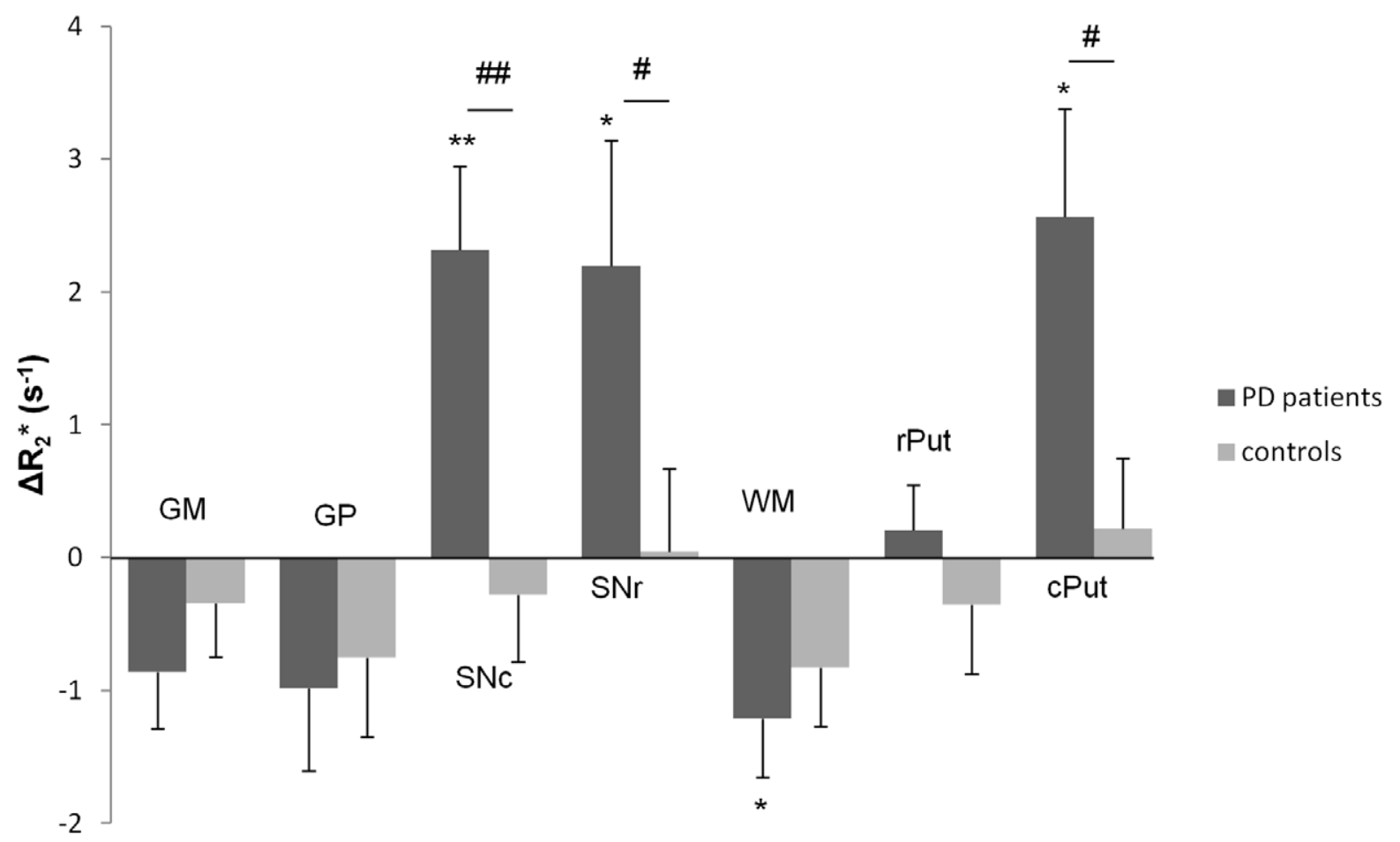

Figure 3. $\Delta \mathbf{R}_{2}{ }^{*}\left(s^{-1}\right)$ in each $\mathbf{R O I}$ (mean \pm standard error). A negative $\Delta R_{2}{ }^{*}$ corresponds to a decrease of $R_{2}{ }^{*}$ after three years follow-up, whereas a positive $\Delta R_{2}{ }^{*}$ corresponds to an increase of $R_{2}{ }^{*}$. GM $=$ gray matter; $G P=$ Globus Pallidus; $S N c=$ Substantia nigra pars compacta; $\mathrm{SNr}=$ Substantia nigra pars reticulata; $\mathrm{WM}=$ white matter; $r \mathrm{Put}=$ rostral putamen; $\mathrm{CPut}=$ caudal putamen. ${ }^{* *}: \mathrm{p}<0.01 ;{ }^{*}: \mathrm{p}<0.05$ (significance of $\Delta \mathrm{R}_{2}{ }^{*}$ by group, signed rank test). \#\#: $p<0.01 ; \#: p<0.05$ (effect of Parkinson's disease on $\mathrm{R}_{2}{ }^{*}$, ANOVA).

doi:10.1371/journal.pone.0057904.9003 
$\mathrm{R}_{2}{ }^{*}$ for Parkinson's Disease Follow-Up

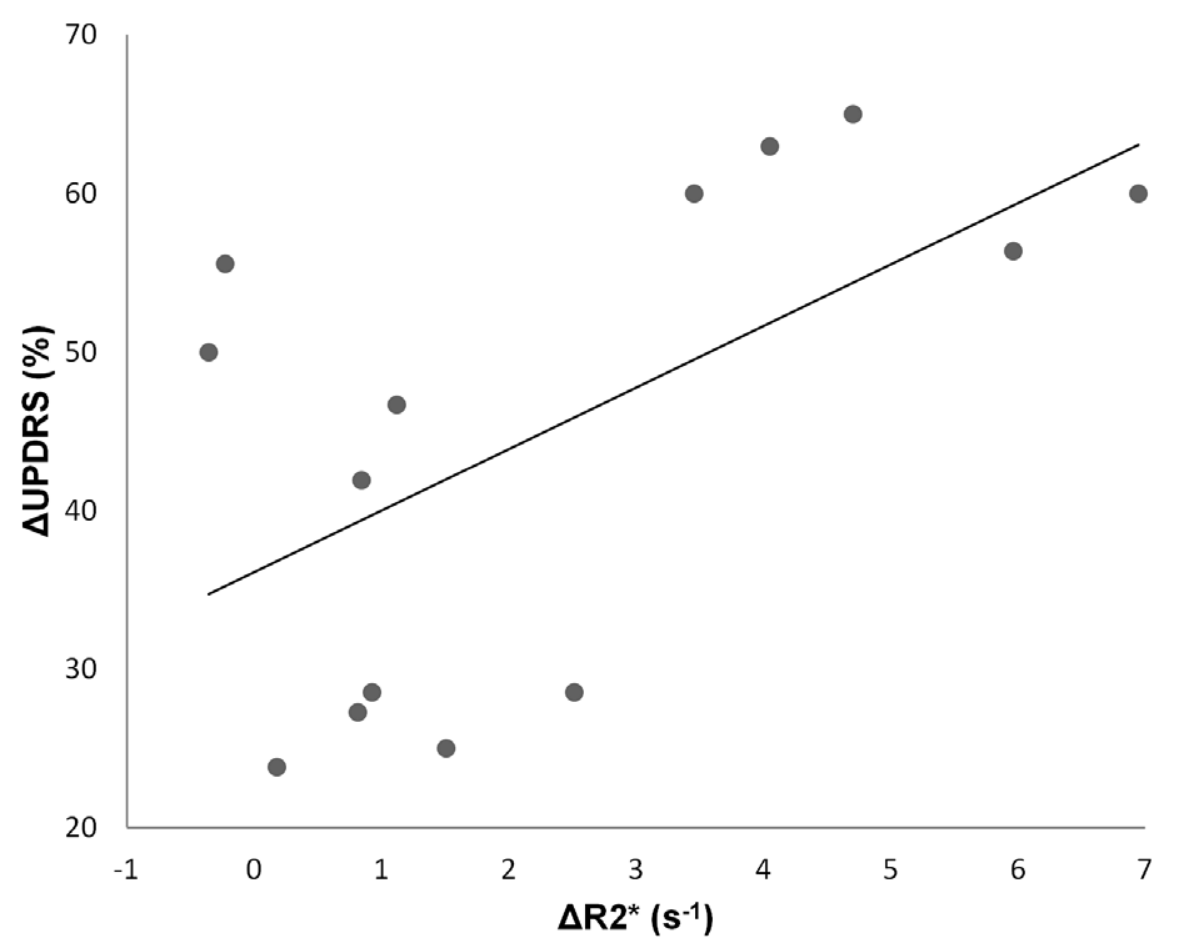

Figure 4. Correlation between $\Delta \mathbf{R 2}^{*}$ and disease worsening. Scatter plot of the correlation between $\Delta \mathrm{R}_{2}{ }^{*}\left(\mathrm{~s}^{-1}\right)$ and $\Delta \mathrm{UPDRS}(\%)$ in $\mathrm{SNc}$ showing a positive correlation (Spearman, $R=0.586, p=0.028$ ). doi:10.1371/journal.pone.0057904.g004

parts of the SN, few works have dealt with them separately. Only Martin et al. [5] analyzed these two structures, reporting an increase of $\mathrm{R}_{2}$ * limited to the lateral part of the $\mathrm{SNc}$, whereas we found a significant increase of $\mathrm{R}_{2} *$ in both parts. This inconsistency could be explained by a different duration of the disease, 3 years on average in the study by Martin et al. instead of 6 years in our study. In addition, the lack of contrast between the two parts of the $\mathrm{SN}$ in the MR images must be emphasized, which introduces uncertainty in ROI positioning and thus may contribute to the differences between the two studies [24]. It should be noted, however, that we used the same method as Martin et al. to place the ROI in the 2 parts of the SN. We did not find any difference between less and most affected sides in the SN whereas a correlation between the lateralized UPDRS motor scores from the clinically most affected side and $\mathrm{R}_{2}{ }^{*}$ values from the opposite $\mathrm{SN}$ was shown in early PD [5]. These differences could again be explained by the longer disease duration of our patients, leading to mainly symmetrical motor signs. Finally we showed no effect of disease duration and $\mathrm{HY}$ stage on $\mathrm{R}_{2}$ * according to the literature $[4,5,7,9,25]$. There is considerable heterogeneity in the rate of progression of $\mathrm{PD}$, which can be influenced by clinical, genetic and external factors, the relative contribution of these factors which remain incompletely understood [26,27]. This interindividual variability in terms of rate of disease progression may explain why our cross-sectional study is insufficient to demonstrate a link between the variables which had been assessed (UPDRS, HY stage and disease evolution) and the $\mathrm{R}_{2}{ }^{*}$. This fact emphasizes the need to perform an individual and longitudinal approach to assess $\mathrm{R}_{2} *$ as a biomarker of disease progression, the patient being his own control.

In the controls, we found an effect of age on $\mathrm{R}_{2} *$ in the putamen (significant in the caudal part) and GM, with an increase in elderly subjects, in agreement with other cross-sectional studies [15$17,28]$. We also observed an increase of $\mathbf{R}_{2} *$ with age in the putamen of PD patients, with results reaching significance only in the rostral part.

\section{Longitudinal Analysis}

In PD patients, in which both aging and disease evolution are involved in the change of iron content estimated with $\mathrm{R}_{2} *$, longitudinal follow-up is the best way of taking these two factors into account. Thus it is likely that the disease itself is the main explanation for the rapid increase of $\mathrm{R}_{2} *$ in the $\mathrm{SN}$ because no change of $R_{2}$ * due to aging was observed in this structure in the control group. In the caudal putamen, although cross-sectional analysis showed higher $\mathrm{R}_{2} *$ in older controls, the longitudinal follow-up did not highlight any significant evolution over three years, demonstrating the predominant role of PD in increasing $\mathrm{R}_{2} *$ in this structure.

The significant variation of $\mathrm{R}_{2}$ * over a short period in structures involved in the physiopathology of PD [29], underlines the sensitivity of this parameter to disease evolution, since the HY stage and UPDRS used to evaluate the severity of the disease were significantly exacerbated over this same period of 3 years. Interestingly, we also found a positive correlation between $\Delta \mathrm{R}_{2}{ }^{*}$ and $\triangle$ UPDRS in SN, providing an additional argument in favor of $\Delta \mathrm{R}_{2} *$ as a biomarker of disease progression.

As the variation of $R_{2} *$ is essentially linked to modifications of iron content, our results suggest rapid accumulation of iron in the $\mathrm{SN}$ and the cPut during disease evolution. This rapid accumulation, particularly in the $\mathrm{SN}$, suggests that iron plays a role in neuronal death mechanisms, in addition to its role as a vulnerability factor described by certain authors [13].

Several hypotheses [30] have been evoked to explain the increase of iron in the SN of PD patients, such as increased penetration of iron in dopaminergic neurons [31-33] and microglial activation [34,35]. The migration of microglial cells in 
the SN, which represents a normal immune response to the degenerative process, could also participate in maintaining this process [35]. At the pathophysiological level, iron participates in the degenerative process as it contributes to the generation of reactive oxygen species inducing oxidative stress [36]. Works on animal models [37] show that the death of dopaminergic neurons precedes iron accumulation. Thus iron may not play a role in the initiation of the degenerative process but its increase as the disease worsening could indicate an important mechanism ensuring its persistence.

However, it is likely that the variations of $\mathrm{R}_{2} *$ observed in this study do not exclusively reflect those of iron concentration. Indeed, the $\mathrm{R}_{2}$ * relaxometry method worked well in brain tissues studied post mortem [29], but correlations observed between $\mathrm{R}_{2}{ }^{*}$ and iron concentration was weaker in vivo [30,31]. A large amount of $\mathrm{R}_{2}$ is non-iron dependent which makes $\mathrm{R}_{2} *\left(\mathrm{R}_{2} *=\mathrm{R}_{2}+\right.$ $\mathrm{R}_{2}{ }^{\text {') }}$ sensitive to the neurodegenerative process that affects water content [38]. Furthermore, $R_{2}{ }^{\prime}$ is very sensitive to brain oxygenation [39] and the arrangement at cellular scale of tissue constituents having different magnetic susceptibilities [18]. Thus we cannot discard the possibility that vascular or microstructural modifications of basal ganglia during the evolution of PD could participate in variations of $R_{2} *$ mainly due to iron accumulation. However, vascular involvement seems unlikely in our subjects, since we did not find any vascular lesion on MRI.

Lastly, we found a reduction of $\mathrm{R}_{2} *$ in the $\mathrm{WM}$ of PD evaluated at $7.5 \%$ over 3 years, a point that has not yet been studied in PD. Siemonsen et al. [17], demonstrated a decrease of $\mathrm{R}_{2} *$ correlated with normal aging, which could be linked with structural modifications of white matter described in elderly subjects, such as demyelination and axonal changes [17]. Interestingly, the

\section{References}

1. Dexter DT, Carayon A, Javoy-Agid F, Agid Y, Wells FR, et al. (1991) Alterations in the levels of iron, ferritin and other trace metals in Parkinson's disease and other neurodegenerative diseases affecting the basal ganglia. Brain 114 (Pt 4): 1953-1975.

2. Bartzokis G, Cummings JL, Markham CH, Marmarelis PZ, Treciokas LJ, et al. (1999) MRI evaluation of brain iron in earlier- and later-onset Parkinson's disease and normal subjects. Magn Reson Imaging 17: 213-222.

3. Baudrexel S, Nurnberger L, Rub U, Seifried C, Klein JC, et al. (2010) Quantitative mapping of $\mathrm{T} 1$ and $\mathrm{T} 2 *$ discloses nigral and brainstem pathology in early Parkinson's disease. Neuroimage 51: 512-520.

4. Gorell JM, Ordidge RJ, Brown GG, Deniau JC, Buderer NM, et al. (1995) Increased iron-related MRI contrast in the substantia nigra in Parkinson's disease. Neurology 45: 1138-1143.

5. Martin WR, Wieler M, Gee M (2008) Midbrain iron content in early Parkinson disease: a potential biomarker of disease status. Neurology 70: 1411-1417.

6. Michaeli S, Oz G, Sorce DJ, Garwood M, Ugurbil K, et al. (2007) Assessment of brain iron and neuronal integrity in patients with Parkinson's disease using novel MRI contrasts. Mov Disord 22: 334-340.

7. Peran P, Cherubini A, Assogna F, Piras F, Quattrocchi C, et al. (2010) Magnetic resonance imaging markers of Parkinson's disease nigrostriatal signature. Brain 133: 3423-3433.

8. Behnke S, Schroeder U, Dillmann U, Buchholz HG, Schreckenberger M, et al. (2009) Hyperechogenicity of the substantia nigra in healthy controls is related to MRI changes and to neuronal loss as determined by F-Dopa PET. Neuroimage 47: 1237-1243.

9. Graham JM, Paley MN, Grunewald RA, Hoggard N, Griffiths PD (2000) Brain iron deposition in Parkinson's disease imaged using the PRIME magnetic resonance sequence. Brain $123 \mathrm{Pt}$ 12: 2423-2431.

10. Ryvlin P, Broussolle E, Piollet H, Viallet F, Khalfallah Y, et al. (1995) Magnetic resonance imaging evidence of decreased putamenal iron content in idiopathic Parkinson's disease. Arch Neurol 52: 583-588.

11. Wallis LI, Paley MN, Graham JM, Grunewald RA, Wignall EL, et al. (2008) MRI assessment of basal ganglia iron deposition in Parkinson's disease. J Magn Reson Imaging 28: 1061-1067.

12. Kosta P, Argyropoulou MI, Markoula S, Konitsiotis S (2006) MRI evaluation of the basal ganglia size and iron content in patients with Parkinson's disease. J Neurol 253: 26-32.

13. Bartzokis G, Tishler TA, Lu PH, Villablanca P, Altshuler LL, et al. (2007) Brain ferritin iron may influence age- and gender-related risks of neurodegeneration. Neurobiol Aging 28: 414-423. decrease of $\mathrm{R}_{2} *$ tended to be significant in our control group. Moreover, no difference was found between PD and controls in longitudinal follow-up. These two last points lead us to presume that age plays a predominant role in explaining the variations of $\mathrm{R}_{2}{ }^{*}$ in the frontal WM observed in our PD patients.

In conclusion, we showed that a significant increase of $\mathrm{R}_{2} *$ was observed longitudinally in substantia nigra and caudal putamen of PD patients, and correlated with clinical markers of disease worsening, emphasizing its interest as a biomarker of the disease's evolution. The result of this longitudinal follow-up, collected from only 18 controls and 14 PD patients, asks to be confirmed on a larger cohort.

Our results suggest that such quantitative MRI relaxometry could be an interesting tool for an individual assessment of the progression of the neurodegeneration due to $\mathrm{PD}$, and it would also be interesting for testing the efficiency of specific iron chelators and disease-modifying treatments. Finally, the sensitivity of relaxation rates to iron content is known to increase with the resonance frequency [20]. Consequently, the magnitude of $\mathrm{R}_{2} *$ variations, over three years, which have been highlighted here at $1.5 \mathrm{~T}$, would be presumably greater with higher magnetic field strength. This provides an opportunity to reduce the follow-up period separating two $\mathrm{R}_{2}$ * measurements, a point which deserves further studies.

\section{Author Contributions}

Conceived and designed the experiments: MU JMB FD. Performed the experiments: MU IR BC. Analyzed the data: MU JMB LO. Contributed reagents/materials/analysis tools: MU JMB. Wrote the paper: MU JMB LO FD.

14. Hallgren B, Sourander $\mathrm{P}$ (1958) The effect of age on the nonhaem iron in the human brain. J Neurochem 3: 41-51.

15. Martin WR, Roberts TE, Ye FQ Allen PS (1998) Increased basal ganglia iron in striatonigral degeneration: in vivo estimation with magnetic resonance. Can J Neurol Sci 25: 44-47.

16. Xu X, Wang Q Zhang M (2008) Age, gender, and hemispheric differences in iron deposition in the human brain: an in vivo MRI study. Neuroimage 40: 35 42 .

17. Siemonsen S, Finsterbusch J, Matschke J, Lorenzen A, Ding XQ et al. (2008) Age-dependent normal values of $\mathrm{T} 2 *$ and $\mathrm{T} 2$ ' in brain parenchyma. AJNR Am J Neuroradiol 29: 950-955.

18. Yablonskiy DA, Haacke EM (1994) Theory of NMR signal behavior in magnetically inhomogeneous tissues: the static dephasing regime. Magn Reson Med 32: 749-763.

19. Ma J, Wehrli FW (1996) Method for image-based measurement of the reversible and irreversible contribution to the transverse-relaxation rate. J Magn Reson B 111: $61-69$

20. Gelman N, Gorell JM, Barker PB, Savage RM, Spickler EM, et al. (1999) MR imaging of human brain at $3.0 \mathrm{~T}$ : preliminary report on transverse relaxation rates and relation to estimated iron content. Radiology 210: 759-767.

21. Gibb WR, Lees AJ (1988) The relevance of the Lewy body to the pathogenesis of idiopathic Parkinson's disease. J Neurol Neurosurg Psychiatry 51: 745-752.

22. Thobois $\mathrm{S}$ (2006) Proposed dose equivalence for rapid switch between dopamine receptor agonists in Parkinson's disease: a review of the literature. Clin Ther 28: $1-12$.

23. Fahn S, Elton RL, and Members of the UPDRS development committee. (1987) Recent Developments in Parkinson's Disease; In S. Fahn CDM, D.B. Calne and M. Goldstein (Eds.), editor. Florham Park (NJ): Macmillan Healthcare Information. 153-163.

24. Eapen M, Zald DH, Gatenby JC, Ding Z, Gore JC (2011) Using high-resolution $\mathrm{MR}$ imaging at $7 \mathrm{~T}$ to evaluate the anatomy of the midbrain dopaminergic system. AJNR Am J Neuroradiol 32: 688-694.

25. Du G, Lewis MM, Styner M, Shaffer ML, Sen S, et al. (2011) Combined R2* and diffusion tensor imaging changes in the substantia nigra in Parkinson's disease. Mov Disord 26: 1627-1632.

26. Evans JR, Mason SL, Williams-Gray CH, Foltynie T, Brayne C, et al. (2011) The natural history of treated Parkinson's disease in an incident, community based cohort. J Neurol Neurosurg Psychiatry 82: 1112-1118.

27. Jankovic J, Kapadia AS (2001) Functional decline in Parkinson disease. Arch Neurol 58: 1611-1615. 
28. Bartzokis G, Beckson M, Hance DB, Marx P, Foster JA, et al. (1997) MR evaluation of age-related increase of brain iron in young adult and older normal males. Magn Reson Imaging 15: 29-35.

29. Agid Y (1991) Parkinson's disease: pathophysiology. Lancet 337: 1321-1324.

30. Gerlach M, Double KL, Youdim MB, Riederer P (2006) Potential sources of increased iron in the substantia nigra of parkinsonian patients. J Neural Transm Suppl: $133-142$

31. Hirsch EC (2006) Altered regulation of iron transport and storage in Parkinson's disease. J Neural Transm Suppl: 201-204.

32. Kortekaas R, Leenders KL, van Oostrom JC, Vaalburg W, Bart J, et al. (2005) Blood-brain barrier dysfunction in parkinsonian midbrain in vivo. Ann Neurol 57: $176-179$.

33. Salazar J, Mena N, Hunot S, Prigent A, Alvarez-Fischer D, et al. (2008) Divalent metal transporter 1 (DMT1) contributes to neurodegeneration in animal models of Parkinson's disease. Proc Natl Acad Sci U S A 105: 18578-18583.

34. Connor JR, Boeshore KL, Benkovic SA, Menzies SL (1994) Isoforms of ferritin have a specific cellular distribution in the brain. J Neurosci Res 37: 461-465.
35. Hirsch EC, Hunot S (2009) Neuroinflammation in Parkinson's disease: a target for neuroprotection? Lancet Neurol 8: 382-397.

36. Zecca L, Youdim MB, Riederer P, Connor JR, Crichton RR (2004) Iron, brain ageing and neurodegenerative disorders. Nat Rev Neurosci 5: 863-873.

37. He Y, Thong PS, Lee T, Leong SK, Mao BY, et al. (2003) Dopaminergic cell death precedes iron elevation in MPTP-injected monkeys. Free Radic Biol Med 35: 540-547.

38. Mitsumori F, Watanabe H, Takaya N (2009) Estimation of brain iron concentration in vivo using a linear relationship between regional iron and apparent transverse relaxation rate of the tissue water at $4.7 \mathrm{~T}$. Magn Reson Med 62: 1326-1330.

39. Punwani S, Cooper CE, Clemence M, Penrice J, Amess P, et al. (1997) Correlation between absolute deoxyhaemoglobin $[\mathrm{dHb}]$ measured by near infrared spectroscopy (NIRS) and absolute R2' as determined by magnetic resonance imaging (MRI). Adv Exp Med Biol 413: 129-137. 